\title{
DOUTRINA
}

\section{Desenvolvimento do Direito de Autor no Brasil após a Lei N.o 5.988/73}

\author{
Antônio Chaves \\ Diretor da Faculdade de Direito da U.S.P. \\ Presidente do Instituto Inter-americano do \\ Direito de Autor (IIDA)
}

\section{Introdução}

Sinto-me feliz com a oportunidade que me oferece a Revue Internationale du Droit d'Auteur de descortinar, para os seus leitores, um panorama que sem dúvida lhes é desconhecido: o da evolução do direito de autor, num país tradicionalmente respeitador dos seus postulados fundamentais, que sempre se alinhou entre os primeiros signatários, no continente americano, das grandes convenções internacionais, de grande potencialidade em todos os ramos da produção e que emerge como potência internacional, com possibilidades de exercer exemplaridade na realização da disciplina entre os países em desenvolvimento.

Começam, com efeito, finalmente, a entrar em funcionamento os órgãos estruturados pela nova lei : o Conselho Nacional de Direito de Autor e o Escritório Central de Arrecadação, sacudindo com tal violência, pela base, todas as posições assentadas, que não podia mesmo deixar de repercutir - como era necessário - num status-quo absolutamente incompatível com as condições atuais da sociedade e com os novos meios de comunicação do pensamento.

Embora com falhas e deficiências, a lei n. $^{0} \quad 5.988$, de 14-2-1973, representa sem dúvida um marco. Deveria substituir os obsoletos dispositivos do Código Civil, ainda sob a epígrafe $D a$ propriedade literária, científica e artística, e dezenas de diplomas legais que procuravam acomodá-los às conquis-

* Colaboração publicada pela Revue Internationale du Droit d'Auteur de julho de 1977 e atualizada. 
tas do cinema, da radiodifusão e da televisão. Longe, porém, de consolidá-los, modernizando-os, ressalva o art. 134 "a legislação especial que com ela for compatível", gerando sempre a incerteza de quais as normas que estão e quais as que não estão mais em vigor.

Um pouco mais de ousadia e de imaginação teria, sem dúvida, tornado modelar a reforma.

Deixemos porém de recriminações e abramos nossos corações à esperança. $\mathrm{O}$ que interessa é acompanhar os primeiros movimentos, as tendências que revelam e as possibilidades que oferecem.

A idéia originária era muito mais ambiciosa: um verdadeiro Código de Direito de Autor e Direitos Conexos, cujo anteprojeto, elaborado pelo ex-Presidente do Tribunal de Justiça do Distrito Federal, Desembargador MLLTON SEBASTIÃo BARBosA, foi publicado no Diário Oficial da União de 16-6-1967, compreendia 351 artigos.

Nomeada a Comissão Revisora, houve cisão de opiniões. o Presidente da mesma, antigo Ministro do Supremo Tribunal Federal, Prof. CÂNDIDo MotTA FilHo, ofereceu um substitutivo de 98 artigos, mantendo os critérios tradicionais, nada inovando. Os demais membros, o mesmo desembargador e o signatário destas linhas, ofereceram um projeto que procurava consubstanciar as conquistas das legislações mais modernas em 198 artigos, distribuídos em três partes: Direito do Autor, Transmissão, Defesa.

A primeira tinha três títulos: Generalidades (a obra, autoria), Atributos (direito moral, e direitos patrimoniais), Limites (duração, restrições e domínio público).

A segunda, dois: Transmissão causa mortis e Transmissão inter vivos. Este, porém, desdobrava-se em vários capítulos relativos à cessão de diversas categorias de obras, bem como à resolução e revogação dos contratos.

A terceira, um só: órgãos, medidas cautelares e sanções (desdobrando-se em seis capítulos, dos quais dois tratavam particularmente das sociedades de defesa dos direitos do autor e conexos e do Conselho Nacional de Direitos do Autor).

Diante do impasse criado, o Governo incumbiu de elaborar um novo projeto o Prof. José CARLOS MOREIRA Alves, então Procurador Geral da República e hoje membro do Supremo Tribunal Federal. Pressionado pela urgência, reduziu o projeto 
de código a um simples projeto de lei, que, em sua redação final, foi publicado no Diário do Congresso Nacional, de 28-11-1973.

Foram apresentadas 233 emendas, a primeira das quais, pelo Senador Franco MonToro, retomava o Projeto BARBosaCHAVES, mas o prazo exígüo de dez dias imposto aos debates não permitiu senão a aprovação de algumas poucas, as mais urgentes.

Promulgada, finalmente, a Lei N. ${ }^{\circ} \mathbf{5 . 9 8 8}$ apresenta 134 artigos divididos em nove títulos: Disposições preliminares; Das obras intelectuais; Dos direitos do autor; Da utilização de obras intelectuais; Dos direitos Conexos; Das associações de titulares de direito do autor e dos que lhe são conexos; Do Conselho Nacional de Direito Autoral; Das sanções à violação dos direitos do autor e direitos que lhe são conexos; Disposições finais e transitórias.

\section{O Direito de Autor no Brasil}

O exercício, do direito de autor no Brasil, assenta, hoje em dia, em três elementos essenciais:

- O Conselho Nacional de Direito Autoral;

- As sociedades arrecadadoras;

- O Escritório Central de Arrecadação e Distribuição.

Examinemo-los sucessivamente.

I. Conselho Nacional De Direito Autoral. órgão supremo, compete-lhe orientar toda a política governamental em matéria de direito do autor. É definido pela lei como "órgão de fiscalização, consulta e assistência, no que diz respeito a direitos do autor e direitos que lhe são conexos".

Suas atribuições, especificadas como estão pelo art. 117, podem ser compendiadas em dois objetos principais:

No âmbito interno, zelar pela exata aplicação das leis e pelo bom funcionamento das associações de titulares de direito de autor e dos direitos conexos, com poder de intervenção e até mesmo de cassação da autorização para funcionarem, de fiscalização dessas entidades e do Escritório Central e Arrecadação e Distribuição; na fixação de normas para a unificação de preços, sistemas de cobrança e distribuição; gerência do Fundo do Direito Autoral, manifestação sobre conveniência de alterar as normas de direito autoral e problemas a ele concernentes. 
No âmbito internacional, zelar de maneira análoga pela exata aplicação dos tratados e convenções internacionais ratificados pelo Brasil; manifestação sobre conveniência de alteração de normas na ordem internacional e sobre os pedidos de licenças compulsórias previstas em tratados e convenções internacionais.

Não podiam ser mais amplas, nem mais importantes, como se vê, para um país, cioso do desenvolvimento em que se lançou de corpo e alma, as atribuições de um órgão destinado a influir decididamente, na política do direito autoral, isto é, naquilo que se espera seja, finalmente, um verdadeiro estímulo às forças vivas da própria nacionalidade, no que têm de mais expressivo, mais criativo e mais representativo.

Foi o Decreto n. ${ }^{0}$ 76.275, de 15-9-1975, que, em seus 12 artigos, organizou o Conselho, fixou-lhe a sede em Brasília e indicou dever constituir-se por cinco elementos, nomeados por três anos, renovando-se os mandatos cada dezoito meses alternadamente, por dois e por três Conselheiros, admitida a recondução uma só vez.

Precisava mesmo a inteira estrutura do direito de autor, no Brasil, receber uma revisão completa nas suas próprias bases, anquilosadas por vícios, deformações e defeitos que causam grande descrédito no âmbito interno e um lamentável desprestígio no âmbito internacional.

Nem poderia ser melhor a orientação governamental: a situação em que se encontrava o direito de autor, no país, era decorrente exatamente da ausência de um órgão superior, habilitado a atender às constantes reclamações, seja por parte dos usuários, como dos próprios titulares dos direitos de autor e direitos conexos, no que diz respeito à cobrança e distribuição dos proventos pecuniários.

A simples exigência da apresentação do rol completo dos associados e das peças ou composições de cada um deles melhoraria as coisas, sabido como é que a maioria das associações pretende vender "pacotes" fechados, nos quais, com algumas músicas mais populares, os usuários são obrigados a ingerir maioria de peças que jamais serão executadas, obrigando os interessados a comprar outros "pacotes" de outras associações.

Mas, nas primeiras providências que tomou, o CNDA ultrapassou as balizas que lhe foram fixadas pelo Decreto $n$. 76.276, avançando um pouco para o território reservado aos órgãos legislativos.

À função administrativo-normativa, abstraindo-nos mesmo da circunstância de não constar da lei básica de direito de autor, 
só pode dizer respeito, na verdade, às regras complementares para a boa execução da lei, sempre com cega obediência aos seus mandamentos, nem sequer sonhando em preencher claros e lacunas, função que não é própria de um órgão "administrativo", por mais "normativo" que possa pretender ser.

A missão de controle de consulta e assistência que lhe incumbe obriga-o de maneira indiscutível e marca-o indelevelmente com a obrigação de limitar-se a traçar preceitos de mera atuação e cooperação construtiva com as associações arrecadadoras de direito de autor, órgãos privados com os quais, bem ou mal, têm aqui contado autores e intérpretes para a arrecadação de seus direitos.

\section{As Associações Arrecadadoras}

Logo na elaboração do seu regimento interno, deixou, o CNDA claro o propósito de eliminar completamente todas as associações arrecadadoras colocando-se em substituição às mesmas.

Não que sejamos contrários à fusão de todas as sociedades arrecadadoras de direitos autorais num organismo único. É, ao contrário, uma tese que defendemos há vinte e cinco anos.

De há muito se reconhece que, embora sejam condenáveis os monopólios e os privilégios, o interesse público justifica às vezes a sua existência. Determinados serviços dificilmente podem ser realizados de maneira eficiente por múltiplos concessionários.

Por isso, ao mesmo passo que a Constituição Federal assegura ( $\$ 23$ do art. 153) o livre exercício de qualquer ofício ou profissão, limita-o à observância das "condições de capacidade que a lei estabelecer", usando assim o Estado de um verdadeiro poder de polícia, que se poderia enquadrar dentro de um título geral de política das profissões.

Desenvolvendo considerações que motivam nossa preferência pela sociedade única - mais do que conveniente, necessária - fazíamos ver, em nossa obra, Direito Autoral de Radiodifusão (São Paulo, Ed. Rev. dos Tribunais, 1952, p. 489) que ninguém mais se dá à discussão das constitucionalidades da Ordem dos Advogados "órgão de seleção, defesa de disciplina da classe dos advogados em toda a República", e que a exclusividade do exercício de certas atividades técnicas definidas em lei em proveito de pessoas cuja competência é igualmente reconhecida pela lei, já existe para engenheiros, médicos, quí- 
micos, farmacêuticos, agrônomos, dentistas, barbeiros, construtores, radiotelegrafistas, jornalistas, enfermeiros, contadores, oficiais de náutica, conferentes de carga, práticos de barra, despachantes aduaneiros, leiloeiros, corretores de fundos públi$\cos$ e muitos outros.
"Uma só sociedade, abrangendo todos os autores e compositores que a ela queiram filiar-se, nada tem de inconstitucional, é prático, viável e unicamente benefícios poderia proporcionar, não só aos interes- sados, como ao público em geral."

Força é convir, todavia, que a solução encontrada apresenta-se altamente lesiva não apenas às próprias associações, que, finalmente, legalmente organizadas, não podem, sem expresso texto de lei, ser sumariamente condenadas ao desaparecimento, mas, outrossim, aos autores e intérpretes, aos usuários de suas obras, ao público em geral e ao próprio Governo.

Ao se cogitar de uma reformulação dos dispositivos legais relativos a tão delicada matéria, duas alternativas são possíveis ao legislador:

1. formar uma entidade autárquica, incumbida de arrecadar, administrar e distribuir os direitos de autores, com todos os inconvenientes e as dificuldades decorrentes do exercício, em setor especializado de uma atividade confiada a poucos conhecedores da matéria, tanto nos escalões de direção como nos técnicos;

2. manter as associações existentes, submetendo-as, porém, a uma fiscalização rigorosa, e dispensando a todas um tratamento uniforme, que estas, por sua vez, proporcionariam a seus associados, por meios de contratos tipo.

Sem coragem para tomar uma diretriz segura, deixou a Lei $n 0^{\circ} 5.988$ às associações a mais ampla liberdade de organização, não aproveitando sequer a magnífica oportunidade, a pretexto de obediência ao princípio da liberdade de associação, para proibir a constituição de outras entidades do gênero.

De qualquer maneira, optou a Lei $n .^{\circ} 5.988$ pela segunda alternativa.

A própria mensagem presidencial ao Congresso consignava:

"Do exame desses títulos, verifica-se que o projeto considera imprescindível para a defesa dos direitos autorais a existência das associações por elas inte- 
gradas, traçando-lhes os princípios básicos indispensáveis ao seu funcionamento para alcançar os objetivos a que se destinar."

Embora salutarmente vedando pertencer o interessado a mais de uma associação da mesma natureza, o título VI (arts. 103 a 115) regula amplamente as associações de titulares de direitos de autor e dos que lhes são conexos, subordinando-as expressamente, para que possam funcionar no país, à prévia autorização do CNDA.

Indica, no art. 106, quais os elementos que os estatutos da associação devem conter, seus órgãos fundamentais, regras pertinentes ao seu bom funcionamento para, finalmente, no art. 115, determinar que organizem um Escritório Central de Arrecadação e Distribuição - ECAD.

O CNDA não poderia ter alterado, sem autorização legislativa prévia e expressa, semelhante orientação. Mas, na verdade o fez, decretando a curto prazo a extinção das sociedades arrecadadoras, devendo entrar em funcionamento no dia 1-1-1977 o referido escritório, com a finalidade precípua de, nos termos da Resolução n. ${ }^{\circ} 1$, arrecadar e distribuir, "em todo o território nacional, com exclusividade", os direitos de execução pública, inclusive através da radiodifusão e da exibição cinematográfica, das composições musicais e fonogramas.

As duas palavras fatídicas, com exclusividade, contêm a condenação à morte das sociedades arrecadadoras.

Exigia 0 art. 23, que os Estatutos do ECAD, que deveriam ser redigidos pelas próprias Associações de Titulares de Direitos de Autor e dos que lhe são conexos, fossem submetidos à aprovação do CNDA até 1-11-1976.

Ainda que pudessem ser formulados, discutidos e julgados bons dentro do prazo tão breve, seria difícil que o ECAD estivesse em condições de colocar em funcionamento o novo e enorme sistema, convocado para substituir as associações que dispõem de centenas de elementos espalhados em todo o território nacional.

Passarão os autores e artistas intérpretes por um fatal período caótico, em que os usuários deixarão de pagar as associações, proibidas como estão de arrecadar a partir de 1-1-1977 sem que o ECAD esteja desde logo em condições de substituí-las.

Duas semanas depois da publicação da referida Resolução, emanou outra relativa à autorização prévia das Associações de 
Titulares de Direitos de Autor e dos que lhes são Conexos para funcionar.

Deixa claro que deverão as associações, na conformidade do art. 133, começar por modificar seus estatutos em função das normas fixadas pela lei.

\section{O Escritório Central de Arrecadação e Distribuição.}

O anteprojeto primitivo do desembargador MILTON SEBASTIÃo BARBoSA continha a proposta da criação de um Escritório Central de Arrecadação destinado, segundo a Exposição de motivos, a ser a pedra angular do sistema, no que tange ao recolhimento dos proventos dos direitos de autor e conexos.

Nas discussões travadas pela Comissão revisora, tivemos oportunidade de sustentar que semelhante escritório manteria todos os inconvenientes decorrentes da atual multiplicidade de associações: filiais a serem estabelecidas nas principais cidades, grande número de funcionários, despesas gerais e burocracia inevitável. Parecia-nos preferível dar ao CNDA maior soma de poderes de verificação e fiscalização das associações e incorporá-las ao funcionamento do sistema. Esses princípios foram escolhidos no projeto revisto, de preferência à proposição anterior, tida como superada.

$O$ alvitre foi, no entanto, reexumado pela Lei n. ${ }^{\circ} 5.988$, que, depois de ter prestado homenagem, nos arts. 103 seguintes, às associações de titulares de direitos do autor e dos que lhes são conexos, decidiu em seu art. 115 que as mesmas associações organizassem, elas próprias, "no prazo fixado e consoante as normas a serem estabelecidas pelo CNDA, um Escritório Central de Arrecadação e Distribuição dos direitos relativos à execução pública, inclusive através da radiodifusão e da exibição cinematográfica, das composições musicais ou lítero-musicais e de fonogramas".

Não há, pois, senão uma interpretação possível. Cabe iniludivelmente ao Conselho estabelecer normas gerais, que às associações não resta outro remédio senão obedecer, para colimar aquela finalidade, desenvolvendo, quando muito, uma ação esclarecedora e persuasiva, de resto utilíssima, não só para orientar os trabalhos, como até mesmo para evitar desperdício de tempo e de esforços decorrentes das frustrações de uma eventual não-aprovação futura pelo CNDA.

Em perfeita harmonia com esse critério, determinou o art. 11 do Decreto n. ${ }^{\circ} 76.275$ que, uma vez instalado, o Conse- 
lho elaborasse o seu regimento interno, "bem como as normas relativas à constituição, funcionamento e fiscalização do Escritório Central de Arrecadação e Distribuição".

Vencido o prazo fixado, decorrido mesmo um lapso posterior razoável de espera, sem que nenhuma das associações existentes manifestasse o menor propósito de colaborar, ou não tivesse conseguido fazê-lo, apesar de sua boa vontade, então sim, com razoabilidade, poderia o CNDA, suprindo-lhes a falta, chamar a si o encargo.

Longe de assumir semelhante posição, baixou desde logo uma série de resoluções que tinham o ECAD como definitivamente constituído.

A matéria é da maior importância e gravidade, ponto de partida para todo o desenvolvimento do direito de autor no Brasil.

Ou se admitia o ECAD como devidamente constituído diante dos textos lembrados (quando menos seja, para pleitear o reconhecimento de sua ilegalidade), ou convinha-se em que ainda não se personalizou, para exigir-se a revogação da Resolução $n .^{\circ} 1 \mathrm{em}$ todos os tópicos que não possibilitam às próprias associações a oportunidade de se organizar, segundo os princípios traçados pela Lei $n .^{0} 5.988$.

Tivemos oportunidade, a pedido da SICAM (Sociedade Independente de Compositores e Autores Musicais), de emanar parecer a propósito da situação, que, juntamente com os de outros colegas, alicerçou pedido de mandado de segurança em que fundamentalmente ela e as demais associações interessadas pediam a revogação da Resolução $n .^{\circ} 1$.

Tendo o Tribunal Federal de Recursos acolhido em parte o pedido, o Conselho Nacional de Direito Autoral, através da Resolução n..$^{\circ}$ 6, de 25-11-1976, revogou, da Resolução n. ${ }^{\circ} 1$, o art. 5. ${ }^{\circ}$ que determinava fosse o ECAD administrado por uma Comissão Executiva de cinco membros, dos quais três inclusive o superintendente e o secretário-administrativo seriam designados pelo presidente do CNDA e dois somente pelas associações integrantes do ECAD.

Prorrogou ainda para o dia 13-12-1976 o prazo fixado até 1-11-1976, para que os Estatutos do ECAD fossem submetidos à aprovação do CNDA.

Foi uma saída honrosa para ambas as partes: para o Conselho, que terá sentido mais próxima a vigilância da Justiça; para as sociedades, que, na firmeza da orientação do 
Conselho, terão percebido ter chegado o momento do saneamento definitivo do ambiente da cobrança dos pequenos direitos e que era necessário submeter-se de bom grado a uma fiscalização rigorosa de seus estatutos, de sua direção e de seus repertórios, bem como submeter a processo de computação eletrônica a aplicação de todas as quantias arrecadadas, e até mesmo, dos contratos de cessão dos direitos, o que será, sem dúvida, altamente positivo, justificando a revolução que se opera com a criação do Conselho.

Instaura-se, assim, defintivamente em nosso país o sistema há tanto tempo em uso de arrecadação e distribuição dos direitos autorais por processamento eletrônico, eliminando completamente os critérios subjetivos os mais diversificados que estavam em uso, e que tantas reclamações ocasionavam.

Papai Noel havia no entanto de trazer um prêmio para as associações bem comportadas, pois em data de 22-12-1976, o CNDA aprovou os estatutos - do Escritório Central de Arrecadação e Distribuição - ECAD — que lhe foram apresentados pela SICAM, a Socimpro, a Sbacem e a SBAT, sociedades de direitos de autor já autorizadas a funcionar. Com o estatuto aprovado, estas sociedades deviam até o dia $10^{\circ}$ de janeiro seguinte instalar o escritório em Brasília e nomear os membros que deveriam integrá-lo.

Cumpria assim, o CNDA os prazos que havia fixado para a definição das normas legais que permitissem o início de funcionamento do ECAD em 1977.

O ano de 1976 foi, sem dúvida, produtivo para o CNDA, regulamentou o escritório central de arrecadação e distribuição, disciplinou o registro da obra intelectual, estruturou o Fundo de Direito Autoral, baixou normas para a unificação de preços e sistemas de arrecadação e distribuição, além de entre outras iniciativas, haver examinado os processos de autorização para funcionamento de sociedades de direitos do autor e de constituição do Escritório Central de Arrecadação e Distribuição.

Outra resolução, de 24-12-1976, fixou as percentagens de dedução da arrecadação de direitos autorais.

Para a manutenção do ECAD, os descontos seriam, primeiro trimestre de 1977 , de $30 \%$, no segundo, de $25 \%$ e no terceiro, de $20 \%$, e, a partir de $1.0^{\circ}$ de outubro, de $15 \%$.

Para o funcionamento das associações, os descontos seriam de $5 \%$ no primeiro semestre de 1977 e de $3 \%$ a partir de 1-7-1977, devendo ser recolhido ao fundo de direito autoral 
o percentual que seria destinado às associações que não foram autorizadas a funcionar.

Medir-se-á a importância do passo decisivo que isto representa para a moralização almejada, sabendo-se que nada menos de 50 e até $60 \%$ das quantias arrecadadas eram dispendidas pelas associações, sempre em luta com a deficiência de pessoal e as grandes extensões territoriais a serem fiscalizadas.

Uma outra resolução firmou as bases de uma unificação das tarifas e do sistema de cobrança e distribuição dos direitos, inclusive os relativos à radiodifusão e projeção cinematográfica.

$\mathrm{Na}$ fixação dos preços dos direitos autorais, os usuários serão classificados em grupos, tipos, níveis e regiões, em função da natureza de sua atividade, de sua capacidade financeira, das regiões sócio-econômicas as quais pertencem.

A distribuição deve ser feita de acordo com o número efetivo das execuçóes das obras, ou, quando impossível, adotados critérios de amostragem.

Os direitos devidos pelas emissoras de rádio e televisão serão calculados sobre a receita bruta faturada aos anunciantes, proveniente das execuções musicais e de fonogramas.

Facilmente se poderão calcular as críticas, reclamações e resistências que o sistema vai provocar por parte de certos meios interessados na manutenção de uma situação que lhes convinha, mas, incompatível com o progresso cultural. Oxalá num setor tão importante, e, no momento histórico, destinado a transpor uma nova etapa nesta evolução do direito de autor no Brasil, até agora apenas teoricamente delineada pela Lei n. ${ }^{\circ}$ 5.988, com a altanaria decorrente das elevadas atribuições que lhe foram conferidas, mas, ao mesmo tempo, disposto a receber de boa mente as observações que lhe foram endereçadas, possa o Conselho encontrar o caminho que permita ao direito de autor alcançar suas verdadeiras finalidades.

\section{O Domínio Público Remunerado. O Fundo do Direito de Autor}

E outro assunto de importância fundamental.

O Projeto BARBosa-Chaves oferecia uma proposição que, com insignificantes alterações, foi aproveitada no art. 48 da Lei, que declara pertencerem ao domínio público:

- as obras cujo prazo de proteção dos direitos patrimoniais expirou; 
- as de autores falecidos sem sucessores;

- as de autor desconhecido, transmitidas pela tradição oral;

- as publicadas em países que não participem de tratados a que tenha aderido o Brasil e que não confiram aos autores de obras aqui publicadas o mesmo tratamento que dispensam aos autores das obras publicadas em seu território.

$\mathrm{O}$ art. 93 (calcado no art. 60 daquele projeto) dispõe, por sua vez, que a utilização, por qualquer forma ou processo que não seja livre, das obras intelectuais pertencentes ao domínio público, depende de autorização do CNDA.

Se a utilização visar lucro, deverá ser recolhida ao mesmo Conselho a importância correspondente a $50 \%$ da que caberia ao autor da obra se for protegida, salvo se se destinar a fins didáticos, caso em que essa percentagem se reduzirá a $10 \%$.

0 art. 119, finalmente, instituiu o Fundo de Direitos Autorais, que tem por finalidade estimular a criação de obras intelectuais, auxiliar órgãos de assistência social das associações e sindicatos de autores e intérpretes, publicar obras de autores novos, custear as depesas do CNDA, bem como o funcionamento do Museu do Conselho.

A matéria foi objeto de Resolução n. ${ }^{\circ} 34$ de 17-8-1976, que faz depender de uma autorização expressa do CNDA não só a utilização das obras intelectuais nacionais e estrangeiras caídas em domínio público, como também a adaptação, tradução, arranjo ou orquestração dessas obras. Objetivando lucro, deverá o requerente esclarecer, em formulário específico, quais os trabalhos que pretende executar.

A resolução fixa da seguinte maneira o montante das retribuições (que, nos termos do art. 93 da lei, devem representar $50 \%$ do que caberia ao autor no caso de utilização de uma obra protegida) :

I - Publicação de livros, obras musicais e gravuras de obras plásticas, para finalidades não didáticas, $5 \%$ (cinco por cento) sobre o preço de venda ao público.

II - Fonogramas, 4,2\% (quatro vírgula dois por cento) sobre o preço de venda, sendo que se em um mesmo suporte material houver obras que não pertençam ao domínio público o cálculo será proporcional. 
III - Representação pública em recintos com cobrança de ingressos 5\% (cinco por cento) sobre o total da arrecadação, e, quando num mesmo espetáculo houver obras que não pertençam ao domínio público, o recolhimento será proporcional ao programa apresentado.

Em se tratando de utilização de obras com finalidades didáticas, os $10 \%$ (dez por cento) que caberiam ao autor serão considerados :

a) para as hipóteses do item I supra, 1\% (um por cento) sobre o preço de venda ao público;

b) para as do item II, $0,84 \%$ (zero vírgula oitenta e quatro por cento) sobre o preço de venda;

c) para as hipóteses do item III, 1\% (um por cento) sobre o total da arrecadação.

0 disposto aplica-se às reproduções e apresentações de obras arranjadas, adaptadas, traduzidas e orquestradas (art. 11) e os editores ou os produtores que pretendem utilizar obra do domínio público são obrigados a facultar ao CNDA o exame da escrituração na parte que corresponde ao Fundo de Direito Autoral, bem como informá-lo sobre o estado da edição ou produção.

Pela primeira vez enfrenta o Brasil o problema das obras em regime de domínio público remunerado, que tanta controvérsia tem levantado nos países que tentaram sua aplicação. $\mathbf{A}$ matéria não é regulamentada nas grandes convenções internacionais e parece chegado o momento para que comece a ser considerada a necessidade de fixar alguns princípios a respeito da matéria, atendendo ao vulto das obras estrangeiras que podem ser aproveitadas. Cumpre, em todo caso, lembrar a distinção fundamental que existe entre a obra caída em domínio público e a sua tradução que por sua vez pode ser protegida. $\mathrm{O}$ que não impede, frente à lei brasileira, que outras traduções, sem aproveitamento de qualquer elemento das já existentes, possam ser levadas a efeito, recaindo assim sob a regulamentação do Conselho Nacional do Direito de Autor.

Editores e gravadores terão, pois, que se adaptar aos novos critérios, o que terá, parece, o resultado altamente positivo de se evitar ou, pelo menos de diminuir o perigo de ver traduções da mesma obra estabelecerem concorrência entre si. 
Muita celeuma tem sido levantada a respeito dessa resolução. Não percebo nela qualquer ilegalidade ou qualquer afronta às Convenções Internacionais.

Nem vejo por que não possa o CNDA cobrar pela concessão de autorização de publicação no Brasil de obras caídas em domínio público, mesmo em língua estrangeira. Paralelamente ninguém poderá se opor a que obras brasileiras caídas em domínio público sejam publicadas em português ou traduzidas para qualquer outra língua além-fronteiras, contanto que não entrem no território nacional sem o pagamento correspondente.

$\mathrm{O}$ art. $\mathrm{V}$ da Convenção de Berna garante aos autores dos países unionistas os mesmos direitos que os concedidos aos autores nacionais, direitos esses, em virtude do art. VII, alínea I, compreendendo a vida do autor e 50 anos depois da sua morte.

Passado esse período as obras caem em domínio público, sob reserva das disposições do art. 6 , bis, relativas ao direito moral. Além disso, o art. xvIII alínea 1 ressalva aplicar-se a convenção a todas as obras que não tenham caído ainda no domínio público nos seus países de origem por ter expirado o prazo de proteção.

Daí se deduz a alusão que faz a resolução citada às convenções especiais já celebradas ou a celebrar confirma a conveniência que apresentaria, em matéria de domínio público remunerado, uma regulamentação internacional.

\section{Antologias e Comentários}

No âmbito judiciário, a decisão mais importante nestes últimos anos foi relativa às antologias. 0 art. $666, n .^{\circ} \mathrm{I}$, do Código Civil não considerava ofensa aos direitos de autor "a reprodução de passagens ou trechos de obras publicadas e a inserção, ainda integral, de pequenas composições alheias no corpo de obra maior, contanto que esta apresente caráter científico, ou seja compilação destinada a fim literário, didático ou religioso, indicando-se porém, a origem, de onde se tomaram os excertos, bem como o nome dos autores".

Com base nesse dispositivo (reproduzido de resto mais resumidamente no art. 49, I, e a da Lei $n .^{\circ}$ 5.938), o poeta CARLOS DRUMOND DE ANDRADE e o romancista AUTRAN DOURADO propuseram ação de indenização contra a empresa Block Editores, que, sem autorização, mas de inteira boa fé, pois confiara 
quanto à legalidade editorial dos trabalhos nos compiladores, reproduzira trechos de obras de ambos.

A circunstância de não acompanhar dita publicação qualquer comentário dos compiladores quanto ao estilo dos autores, quanto às suas imagens, ou quanto à técnica, levou os Ministros da Primeira Turma do Supremo Tribunal Federal à conclusão, em data de 30-11-1976, de que não podia ser aceita a defesa da editora baseada no cunho didático do livro, reformando, assim, a decisão do Tribunal de Justiça do Estado da Guanabara.

0 mais interessante é o aspecto constitucional assumido pela questão. Com efeito, o art. 153, § 25, da Constituição de 1969 assegura aos brasileiros e aos estrangeiros residentes no país, autores de obras literárias, artísticas e científicas, o direito exclusivo de utilizá-las, direito esse transmissível por herança pelo tempo que a lei fixar.

0 emprego da palavra grifada, substituindo a expressão reproduzi-las, constante do texto correspondente da Constituição de 1946, de âmbito evidentemente mais restrito, assinala uma evolução importante.

O Ministro BILAC PINTo, em longo e erudito voto em que estabelece comparação entre os dispositivos da Lei brasileira e os dos principais países do mundo, chegou à conclusão de que a norma do Código Civil estava revogada: sempre que houver reprodução de obra literária, terá direito o autor à indenização.

Os modernos e variados meios de comunicação como a televisão, o computador e o cinema haviam agravado consideravelmente o problema da autoria das obras de criação intelectual e seu amparo. Como não podia deixar de ser, o direito procura acelerar a sua evolução, para ficar em condição de assegurar a proteção do autor e invocou, a título de exemplo, as legislações de França, da Grã-Bretanha e da Alemanha Federal.

Foi o ponto de vista que prevaleceu, por três votos contra um, sem embargo de não estar concluído o julgamento, em virtude de pedido de vista formulado pelo Presidente da Turma, Ministro ELOY DA RochA, a vitória dos antologiados, condenada a editora a pagar $\operatorname{Cr} \$ 30.000,00$ aos dois escritores.

Embora a quantia seja irrisória, tem uma grande significação moral, principalmente no momento em que a literatura brasileira, vencendo a barreira decorrente da pouca divulgação da língua portuguesa e da dificuldade de encontrar tradutores idôneos, começa a ser mais amplamente propagada no estrangeiro. 
Implicando o acórdão do Supremo a revogação do mencionado inciso do Código Civil, terá que ser tal fato proclamado pelo Senado Federal e não poderá deixar de ter reflexos também no texto atual da Lei n. $\mathbf{5 . 9 8 8 . ~}$

\section{O Estudo do Direito de Autor, Publicações}

O interesse despertado por algumas aulas de Direito de Autor que ministrei no ano de 1970 , no Curso de Direito Civil da Faculdade de Direito da Universidade de São Paulo, ocasionou a criação de uma cadeira dessa matéria em nível de pósgraduação, que venho ministrando desde 1973, em dois semestres.

Isto permitiu a formação de vários especialistas, alguns dos quais defenderam teses do maior interesse: WALTER MoRAIS, Artistas Intérpretes e Executantes, Ed. Revista dos Tribunais, 1976, 341 páginas ; FÁBIO DE MATTIA, O Autor e o Editor da Obra Gráfica. Direitos e Deveres, Saraiva, 1975, 396 páginas (publicou também Estudos de Direito de Autor, pela mesma editora, 1975, 112 páginas); CARlos Alberto BITTAR, O Direito de Autor na Obra Feita sob Encomenda, 172 páginas, Ed. Rev. dos Tribunais, 1977.

Fora desse ambiente, merecem ainda referência as seguintes monografias: HeRMANo DuRVAl, $A$ Publicidade e a Lei, São Paulo, Ed. Rev. dos Tribunais, 1975, 170 páginas; BRUNo JoRGE HAMMES, Elementos básicos, do Direito de Autor Brasileiro, S. Leopoldo, Unisinos, 1976, 239 páginas; e uma Consolidação das Normas de Direito de Autor, de autoria do advogado da SICAM, Hércules Tercino Sanches, São Paulo, Sicam, 1973.

\section{o Instituto Interamericano de Direito de Autor (IIDA)}

Por iniciativa de NATÁlIo CHEDIAK, bem conhecido internacionalmente, durante a XVIII Conferência da Federação Interamericana de Advogados (FIA), celebrada no Rio de Janeiro, em agosto de 1973, foi criado o Instituto Interamericano de Direito de Autor (IIDA), que, em homenagem ao fato de ter sido a referida Faculdade a primeira a ministrar um curso regular da matéria, escolheu-a como sede do novo Instituto, outorgando a mim a desmedida honra de sua presidência.

O IIDA, associação internacional de caráter privado e sem fim lucrativo, cujo objetivo é incrementar o estudo e o progresso dos direitos de autor nas Américas, coordenando os esforços de especialistas e de entidades desejosos de contribuir para a 
defesa mais eficaz dessas prerrogativas, adquiriu personalidade jurídica em 17-4-1974, data em que seus estatutos foram registrados sob n. ${ }^{\circ}$ 58.702, no Cartório Medeiros, em São Paulo.

Vencendo dificuldades econômicas, tem promovido, em obediência ao que determinam seus estatutos, ou participado de numerosas atividades.

Assim, no âmbito internacional, no ano de 1974, participou no mês de outubro, do Seminário Interamericano de Direito de Autor, celebrado em Quito, onde apresentamos uma tese sobre Direitos dos Artistas Intérpretes e Executantes, e tomamos parte nas discussões de dois projetos de lei equatoriana, assistidas também por representantes da Argentina, do México, do Equador, da Venezuela e do Paraguai. Em suas linhas gerais, foram aceitas as diretrizes do Projeto BARBosa-CHAVES, um exemplar do qual foi deixado em mãos do Relator, o licenciado RAMón OBón LeON, do México.

Pouco tempo depois, ao Seminário Latino-Americano sobre Direito de Autor, promovido pelo Centro Regional para o Fomento do Livro na América Latina, da Unesco, comandado por ARCADIo Plazas, comparecemos, eu, que fiz uma exposição sobre o Desafio da Reprografia à Proteção do Direito de Autor, Hermano Duval, oferecendo Contratos de Cessão, de Licença $e$ da Edição no Direito Internacional Privado, $e$ FÁBIO DE MatTia, Direito de Seqüela nas Obras Intelectuais.

Em outubro, de 1975, ao Seminário Latino-Americano sobre Proteção dos Artistas Intérpretes ou Executantes, Produtores de Fonogramas e Organismos de Radiodifusão, patrocinado pelo Governo Mexicano, Unesco, BIT e oMPI, compareceu WALTER MoRAIs, e expôs com sucesso as conclusões de sua tese sobre Direitos dos Artistas Intérpretes e Executantes.

Merece ser assinalado também o trabalho de divulgação do direito de autor desenvolvido pelo Francisco PoNCE ESCALANTE, representante na América Central do IDA, em El Salvador.

No âmbito interno, o IIDA realizou, no mês de março de 1976, uma série de palestras sobre direito de autor nas obras arquitetônicas na sede do Sindicato dos Arquitetos, em São Paulo, e 10 conferências, sob os auspícios da Universidade da Paraíba, em João Pessoa.

No mês de agosto, no III Salão de Humor de Piracicaba, fizemos uma exposição sobre o Direito de Autor do Cartunista $e$ do Desenhista em Quadrinhos, daí resultando, pelos 500 
participantes, a decisão de formarem a associação Paulista do Artista Gráfico vinculada a publicações culturais e periódicas, e na III Semana de Estudos de Editoração, junto à Iv Bienal do Livro, fizemos uma exposição sobre a Proteção Legal do Autor $e$ do Editor, com vistas principalmente ao problema das apostilas, da reprografia e de outras reproduções não autorizadas.

Em setembro de 1976, o IIDA promoveu, em Brasília, seu III Ciclo de Estudos Autorais, proporcionando aos participantes um verdadeiro curso de direito de autor, com duração de 30 horas, dando-lhes direito de obterem um certificado de freqüência com título de extensão universitária. Houve participação de eminentes autoralistas dos Estados Unidos, da Argentina, da Venezuela e do México.

De 5 a 10 de junho de 1977 realizaram-se em São Paulo, promovidos pelo IIDA, sob os auspícios da Organização Mundial de Propriedade Intelectual (oMPI) a Primeira Conferência Continental de Direito Autoral e o $1^{\circ}$ Congresso Brasileiro de Direito Autoral.

Tendo como tema geral $O$ Direito Autoral nas Américas, foram desenvolvidos os seguintes painéis: A Atuação das Organizações Internacionais; Diretrizes para o Desenvolvimento do Direito Autoral nas Américas; Repressão Penal e Civil às Violações de Direitos Autorais; Sistema de Remuneração e Arrecadação de Direitos Autorais - A Realidade Brasileira e Internacional; Proteção à Arte Aplicada; Reprografia; Direitos Conexos; o Domínio Público Remunerado e o Problema Editorial Brasileiro, com participação de representantes da OMPI, da UNESCO, do México, Argentina, Colômbia, Chile, Bolívia e Estados Unidos da América do Norte.

Finalmente, o IDA recebeu, do Instituto de Pesquisas, Estudos e Assessorias do Congresso (IPEAC) solicitação, provocada pelo Senador Franco MonToro, de uma pesquisa sobre a legislação autoral não revogada pela Lei $n .^{\circ} 5.988$, decidindo, então, realizar uma Consolidação de todas as disposições em vigor, tarefa para a qual solicitou o prazo de um ano. 